\title{
The plasticizing effect of properties of manganous chloride and glycerin on poly(vinyl alcohol)
}

\author{
Puyou Jia ${ }^{1}$, Meng Zhang, ${ }^{1,}$, Caiying Bo ${ }^{1}$, Lihong Hu${ }^{1,2}$, Yonghong Zhou ${ }^{1 *}$ \\ ${ }^{1}$ Chinese Academy of Forest (CAF), Institute of Chemical Industry of Forest Products, Jiangsu Province, Nanjing 210042, \\ China \\ ${ }^{2}$ Chinese Academy of Forest (CAF), Institute of New Technology of Forestry, Beijing 100091, China \\ "Corresponding author: e-mail: yhzhou777@sina.com
}

\begin{abstract}
Poly(vinyl alcohol) films were prepared with manganous chloride $\left(\mathrm{MnCl}_{2} \cdot 4 \mathrm{H}_{2} \mathrm{O}\right)$ and glycerin as complex plasticizer. The micro morphology of pure PVA film and complex plasticizer plasticized PVA films was observed by scanning electron microscope (SEM). The interaction between complex plasticizer and PVA molecules was investigated by Fourier transform infrared spectroscopy (FT-IR). The influence of complex plasticizer on crystalline, thermal and mechanical properties of PVA films was studied by X-ray diffraction (XRD), differential scanning calorimetry (DSC), thermogravimetric analysis (TG), and tensile testing, respectively. The results showed that the complex plasticizer of $\mathrm{MnCl}_{2} \cdot 4 \mathrm{H}_{2} \mathrm{O} /$ glycerin could interacted with PVA molecular and then effectively destroy the crystals of PVA. PVA films plasticized with complex plasticizer of $\mathrm{MnCl}_{2} \cdot 4 \mathrm{H}_{2} \mathrm{O}$ /glycerin became soft and ductile, with lower tensile strength and higher elongation at break compared with PVA films. This is an important cause of plasticization of the complex plasticizer of $\mathrm{MnCl}_{2} \cdot 4 \mathrm{H}_{2} \mathrm{O} /$ glycerin on PVA films.
\end{abstract}

Keywords: poly(vinyl alcohol), glycerin, manganous chloride, blend, film.

\section{INTRODUCTION}

Poly(vinyl alcohol) (PVA) is an important polymer and is widely used as films, hydrogels, adhesives and paper coating agents ${ }^{1-3}$, because of its unique characteristics of being available in large quantities and at low prices. PVA exhibits good mechanical strength, water solubility, biodegradability, improved barrier properties, heat stability and applicability in industrial processing ${ }^{4-7}$. These excellent properties are due to its unique multi-hydroxyl structure and small size of the hydroxyl substituent groups that allows essentially ataxic PVA to crystallize. Because of the high level of hydrogen bonding in the crystals, PVA is provided with a high-melting point. This makes the melting point close to its decomposition temperature that the thermal processing of PVA is difficult ${ }^{\mathbf{8}, \boldsymbol{9}}$. The thermal processing of PVA is usually improved by adding plasticizers and thermal stabilizers ${ }^{10-13}$. Plasticizers could effectively improve the mechanical and thermal properties of PVA by adding them in PVA matrix ${ }^{14}$. It is important for the application and development of PVA to change the mechanical and thermal properties of PVA by using plasticizers. There are many researchers have studied the plasticization of PVA with many different plasticizer such as glycerin, polyethylene glycol and some organic compounds which could change the mechanical and thermal properties of PVA by forming strong hydrogen bonding with the hydroxyl groups of PVA, the hydrogen bonding between the PVA and plasticizer can replace the intermolecular hydrogen bonding and then improve the flexibility of PVA films ${ }^{15-17}$.

Recently some researchers have paid more attention on the effect of various metal salts on the thermal, optical, crystalline and electrical of PVA ${ }^{18-19}$. They have proved that the metals salts had an obvious effect on the mechanical, thermal and optical properties on PVA. The structure modification depending on the content and the species of metals salts. Xiancai Jiang et al. reported that the mechanical and thermal properties of
PVA was improved with the addition of Calcium nitrate $\left(\mathrm{Ca}\left(\mathrm{NO}_{3}\right)_{2}\right)^{20-21}$.

The objective of this article is to illustrate the plasticizing effect of complex plasticizer of $\mathrm{MnCl}_{2} \cdot 4 \mathrm{H}_{2} \mathrm{O} /$ glycerin on PVA. The effect of complex plasticizer of $\mathrm{MnCl}_{2} \cdot 4 \mathrm{H}_{2} \mathrm{O} /$ glycerin on the mechanical, crystalline and thermal properties of PVA were studied.

\section{EXPERIMENTAL SECTION}

\section{Material}

PVA $(\mathrm{DP}=2400)$ was provided by ShangHai Yingjia Industrial Development Co., Ltd, Analytical grades of glycerin, $\mathrm{MnCl}_{2} \cdot 4 \mathrm{H}_{2} \mathrm{O}$ was kindly supplied by Nanjing Chemical Reagent Co., China.

\section{Sample preparation}

PVA films were prepared by the casting method. $3 \mathrm{~g}$ PVA and $2 \mathrm{~g}$ complex plasticizer (the mass ratio of $\mathrm{MnCl}_{2} \cdot 4 \mathrm{H}_{2} \mathrm{O}$ and glycerin is 3:1) were dissolved in $120 \mathrm{~g}$ distill water at $95^{\circ} \mathrm{C}$ and stirred for $2 \mathrm{~h}$, then 5 wt.\% PVA aqueous solutions were prepared, the solution were casted onto the Petri dishes and dried at room temperature for one week to eliminate water. The PVA films without complex plasticizer were prepared in the same way. All the films were stored at relative humidity of $54 \%$ for one week before testing.

\section{Infrared spectroscopy (FTIR)}

The FTIR studies were carried out using a Nicolet iS10 FT-IR (Nicolet Instrument Crop., America). The spectra were acquired in the range of 4000 to $650 \mathrm{~cm}^{-1}$ at a resolution of $4 \mathrm{~cm}^{-1}$.

\section{Mechanical properties}

Tensile modulus, tensile strength, and elongation at break were determined according GB/T 1040.1-2006 (China) under ambient conditions, using E43.104 Universal 
Testing Machine (MTS Instrument Crop., China). The reported values were the average of at least.

\section{TG Analysis}

TGA was carried out in a TG209F1 TGA thermal analysis instruments (Netzsch Instrument Crop., German) in $\mathrm{N}_{2}$ atmosphere $(50 \mathrm{ml} / \mathrm{min})$ at a heating rate of $10^{\circ} / \mathrm{min}$. The samples was put into platinum pans and scanned from ambient temperature to $600^{\circ} \mathrm{C}$.

\section{DSC Analysis}

DSC was performed by a Diamond DSC differential scanning calorimeter (PE Instrument Crop., America). Slices of PVA and modified PVA films with total of 6 $\mathrm{mg}$ were weighted and sealed in aluminum pans. The temperature of pans is from $-60^{\circ}$ to $80^{\circ} \mathrm{C}$ at a heating rate of $20^{\circ} \mathrm{C} / \mathrm{min}$ under a flow of nitrogen.

\section{Scanning electron microscopy (SEM)}

The cross section of films was observed on a 3400-I SEM (Hitachi Instrument Crop., Japan). The samples were first freeze fractured by liquid nitrogen. The fracture surfaces were vacuum coated with gold and examined with the acceleration voltage of $20 \mathrm{kV}$.

\section{$\mathrm{X}$-ray diffraction measurements}

$\mathrm{X}$-ray diffraction patterns were recorded in the reflection mode in the angular range of $5-50^{\circ} \mathrm{C}$ (2theta) at ambient temperature by a D8 FOCUS diffractometer (Bruker Instrument Crop., German). The radiation from the anode, operating at $50 \mathrm{kV}$ and $35 \mathrm{~mA}$, monochromized with a nickel foil, the measurements were performed at a scanning speed of 2 theta $=0.06^{\circ} \mathrm{C} / \mathrm{s}$.

\section{RESULTS AND DISCUSSIONS}

\section{FTIR}

There are many hydroxyl groups on PVA chains and they can form hydrogen bonding easily. The crystalline, thermal and mechanical properties of PVA can be affected by the intensity of the hydrogen bonding in PVA. The common plasticizers for PVA such as glycerol and polyethylene glycol can form the hydrogen bonding with PVA molecules. In the interactions, the intensity of of the intermolecular and intramolecular hydrogen bonding between PVA would be reduced. The recent studies showed that the intensity of the interaction between the

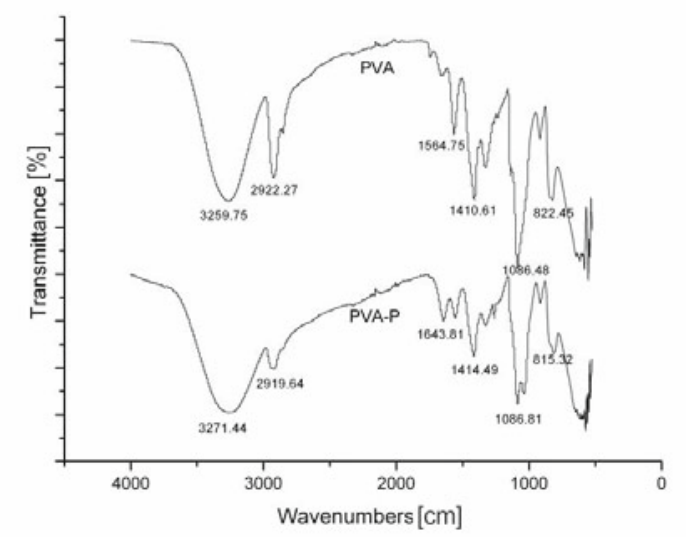

plasticizer and PVA is critical for the plasticizing efficiency of the plasticizer. It is an efficiency way to study the hydrogen bonding for in the infrared region using FTIR, the vibrations of molecules can be investigated. The pure PVA and PVA plasticized with $\mathrm{MnCl}_{2} \cdot 4 \mathrm{H}_{2} \mathrm{O} /$ glycerin were obtained and shown in Figure 1. There is no absorption band of free "-OH" at $3600 \mathrm{~cm}^{-1}$ for PVA. This indicates the hydroxyl groups are generally associate with the intermolecular and intramolecular hydrogen bonding. It was shown in Figure 1 that the absorption band of "-OH" shift to a higher wave number after the addition of $\mathrm{MnCl}_{2} \cdot 4 \mathrm{H}_{2} \mathrm{O} /$ glycerin. The shift in the frequency is valuable as the measurement of the hydrogen bonding of the hydroxyl group. It indicates that the hydrogen banding is weakened when the frequency shifts to a higher value. From the Figure 1, the spectrum of pure PVA showed the absorption of hydroxyl at $3259 \mathrm{~cm}^{-1}$, the absorption band of hydroxyl shifted to a higher value at $3271 \mathrm{~cm}^{-1}$ with the addition of $\mathrm{MnCl}_{2} \cdot 4 \mathrm{H}_{2} \mathrm{O} /$ glycerin, it indicated that the addition of $\mathrm{MnCl}_{2} \cdot 4 \mathrm{H}_{2} \mathrm{O}$ /glycerin would reduce the intensity of the hydrogen of bonding of PVA molecules. It is because $\mathrm{MnCl}_{2}$ can form strong interaction with PVA molecules and glycerin can form strong hydrogen bonding with PVA, which takes place of the hydrogen bonding between the hydroxyl groups of PVA molecules. The commonly used plasticizers for PVA are organic compounds such as glycerol, urea and caprolactam which only form hydrogen bonding with PVA molecules, the work in this article, the glycerin forms hydrogen bonding with PVA molecules and $\mathrm{MnCl}_{2}$ can form strong interaction with PVA molecules, they both reduce the intensity of the hydrogen bonding in PVA, it showed that $\mathrm{MnCl}_{2} \cdot 4 \mathrm{H}_{2} \mathrm{O} /$ glycerin have a plasticizing effect for PVA.

\section{Mechanical properties}

The tensile strength, elongation at break and Young's modulus of PVA films and PVA-P films were tested using E43.104 Universal Testing Machine, the mechanical properties were shown in Table.1. From the Table. 1, we can see that the plasticized PVA shows different mechanical properties when compared with pure PVA, with a concurrent decrease in the tensile strength and increasing in the elongation at break with decreasing in Young's modulus. It is accordance with the common rule that the plasticizer can increase the elongation at break and decrease the tensile strength Young's modulus. We interpreted that the change of mechanical properties arises from the degree of the crystallinity. The entanglement and interaction between PVA chains was weak and then the tensile strength and Young's modulus decreased when the PVA was with a lower crystallinity. Because the complex plasticizer was with higher plasticizing efficiency, PVA would be more completely melted to form a continuous phase and thus show better mechanical properties.

Table 1. Mechanical properties of PVA and PVA-P

\begin{tabular}{|l|c|c|}
\hline Sample & PVA & PVA-P \\
\hline Tensile strength [MPa] & 30.2 & 16.1 \\
\hline Elongation at break [\%] & 372.3 & 737.4 \\
\hline Young's modulus [MPa] & 892.1 & 29.9 \\
\hline
\end{tabular}




\section{TG Analysis}

The thermal ability of pure PVA films and PVA plasticized with $\mathrm{MnCl}_{2} \cdot 4 \mathrm{H}_{2} \mathrm{O} /$ glycerin (PVA-P) films were investigated by the TGA. The TGA curves of pure PVA films and PVA-P films are shown in the Figure 2, From the Figure 2, there is a two-step mechanism for the thermal degradation of PVA, the thermal ability of $\mathrm{MnCl}_{2} \cdot 4 \mathrm{H}_{2} \mathrm{O}$ / glycerin plasticized PVA is lower than pure PVA, the decomposition temperature $\left(\mathrm{T}_{\mathrm{d}}\right)$ is determined as the temperature of $5 \%$ thermal weight loss, the $T_{d}$ values of pure PVA and PVA-P is $195^{\circ}$ and $150^{\circ} \mathrm{C}$ were analyzed. The thermal weight loss rate value increased from $14 \%$ to $18 \%$ at $200^{\circ} \mathrm{C}$, it indicated that the thermal degradation of PVA-P is easier than PVA at $200^{\circ}$ C.The thermal degradation of PVA is initiated from the amorphous phase and extends to the crystalline region after the melting. The thermal stability of PVA is determined by the intensity of hydrogen bonding, the addition of $\mathrm{MnCl}_{2} \cdot 4 \mathrm{H}_{2} \mathrm{O} /$ glycerin destroyed the crystals of PVA and decreased the degree of crystallinity of PVA. The PVA-P showed a lower thermal stability than PVA, because the amorphous PVA was easily to start the thermal degradation. We can notice that the reside rate of PVA at $600^{\circ} \mathrm{C}$ could significantly improve with addition of $\mathrm{MnCl}_{2} \cdot 4 \mathrm{H}_{2} \mathrm{O} /$ glycerin, because the residue rate of $\mathrm{MnCl}_{2} \cdot 4 \mathrm{H}_{2} \mathrm{O} /$ glycerin at $600^{\circ} \mathrm{C}$ is higher than that of PVA. Previous some studies show that the high value of residue rate may imply the good flame retardance of the material. It shows that the $\mathrm{MnCl}_{2} \cdot 4 \mathrm{H}_{2} \mathrm{O}$ in complex plasticizer can be used as a retardant plasticizer for PVA.

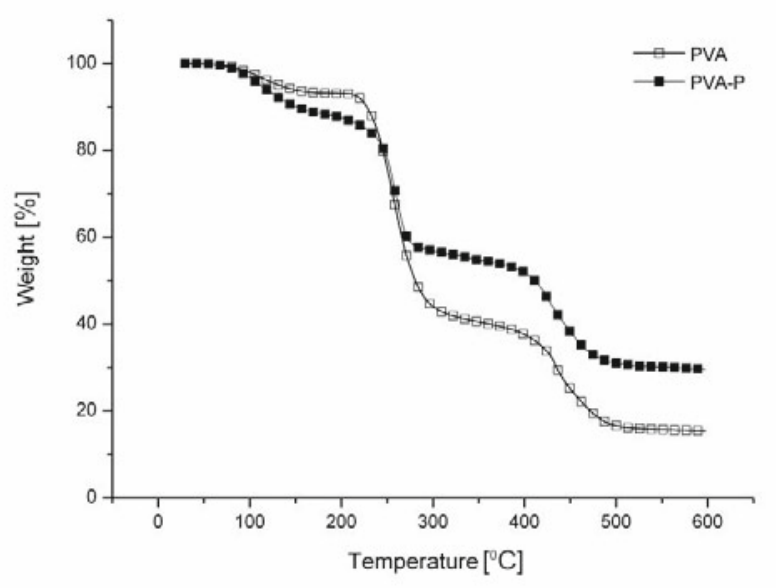

Figure 2. TGA curves of pure PVA and PVA-P

\section{DSC Analysis}

The influence of $\mathrm{MnCl}_{2} \cdot 4 \mathrm{H}_{2} \mathrm{O} /$ glycerin on $\mathrm{tg}$ of PVA was determined by DSC measurement. The DSC measurement was carried out from $-60^{\circ} \mathrm{C}$ to $80^{\circ} \mathrm{C}$ at a heating rate of $20^{\circ} \mathrm{C} / \mathrm{min}$. The obtained DSC curves are shown in Figure 3. From the Figure 3, with the addition of $\mathrm{MnCl}_{2} \cdot 4 \mathrm{H}_{2} \mathrm{O} /$ glycerin the $\mathrm{tg}$ decreased from $21.56^{\circ}$ to $0.01^{\circ} \mathrm{C}\left(\mathrm{t}_{1}\right)$, the decrease of $\operatorname{tg}$ indicated that the chain mobility of PVA decreased. The reason is that $\mathrm{MnCl}_{2} \cdot 4 \mathrm{H}_{2} \mathrm{O} /$ glycerin could interact with PVA molecular hydrogen bonding within the PVA molecules is interrupted.

\section{Scanning electron microscopy (SEM)}

PVA and $\mathrm{MnCl}_{2}$, glycerin molecules could associate with each other by intermolecular and intramolecular

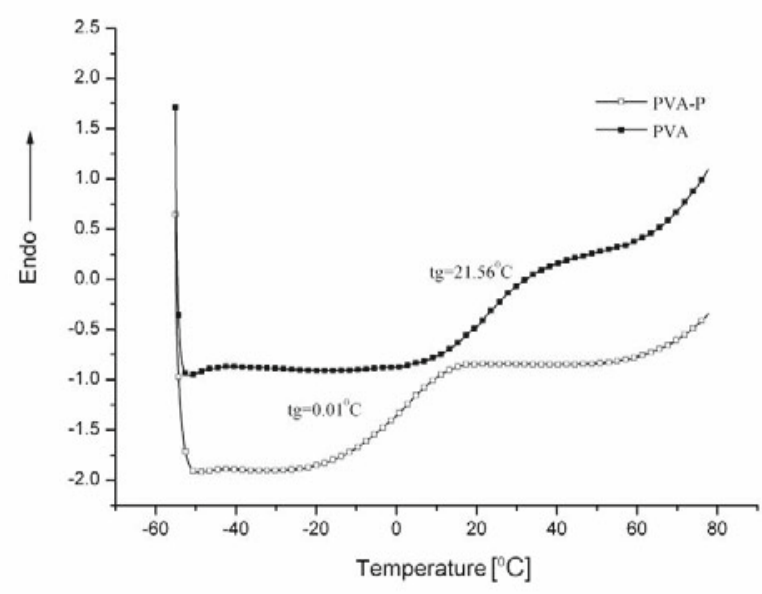

Figure 3. DSC curves of PVA and PVA-P

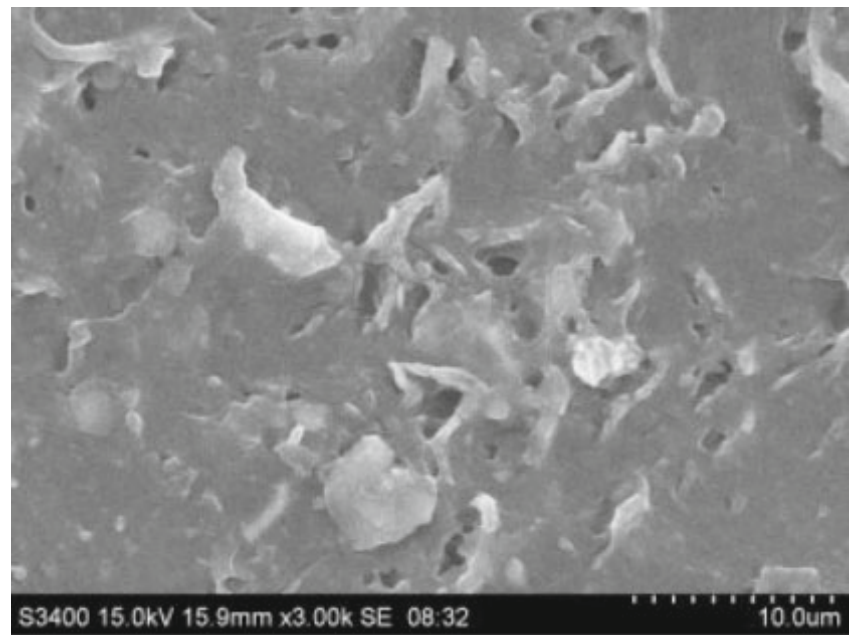

Figure 4. SEM micrograph of PVA

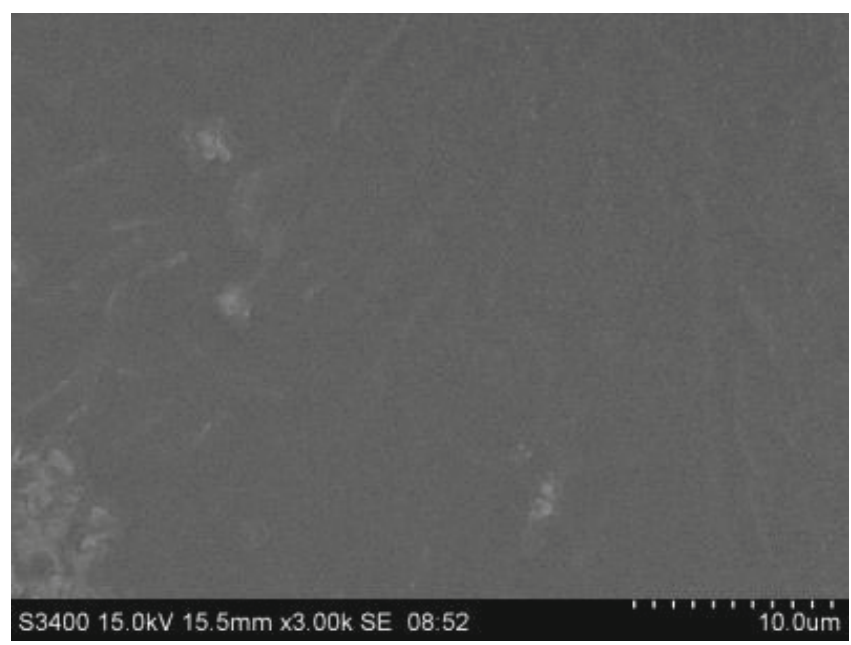

Figure 5. .SEM micrograph of PVA-P

hydrogen bonding. It can be seen with naked eyes that PVA films would become more homogeneous and ductile with the addition of $\mathrm{MnCl}_{2} \cdot 4 \mathrm{H}_{2} \mathrm{O} /$ glycerin. Figure 4 and Figure 5 show the SEM figures of the cross section of pure PVA films and PVA films plasticized with $\mathrm{MnCl}_{2}$ and glycerin. It was observed from Figure 4 and Figure 5 that with the high temperature, pressure, and the action of complex plasticizer, PVA granules were physically broke up small fragments and molten.

PVA form a homogeneous phase with the addition of $\mathrm{MnCl}_{2} \cdot 4 \mathrm{H}_{2} \mathrm{O} /$ glycerin and no $\mathrm{MnCl}_{2}$ chloride crystals 
were observed. This indicated that $\mathrm{MnCl}_{2} \cdot 4 \mathrm{H}_{2} \mathrm{O} /$ glycerin could effectively improve the compatibility of PVA. The improvement of the compatibility of PVA should be attributed to that $\mathrm{MnCl}_{2} \cdot 4 \mathrm{H}_{2} \mathrm{O} /$ glycerin could effectively destroy the crystals of PVA. The entanglements and interaction of PVA molecules would be enhanced when the crystals were destroyed. The mechanical properties of PVA films would be greatly enhanced when the compatibility of PVA was improvement.

\section{X-ray diffraction measurements}

The X-ray diffraction patterns of pure PVA and plasticized PVA films are shown in Figure 6. The pure PVA films exhibited the diffuse characteristic pattern of an amorphous phase with the main halo of the typical peak at 2 theta $=19.8^{\circ} \mathrm{C}$. Comparing the pure PVA with that plasticized PVA, the diffraction peaks of plasticized PVA film almost disappeared with the addition of complex plasticizer. This indicated that the addition of complex plasticize could effectively destroy the crystals of PVA. This is because that $\mathrm{MnCl}_{2} \cdot 4 \mathrm{H}_{2} \mathrm{O} /$ glycerin could form strong interaction with PVA molecules and this interaction would interrupt the intermolecular hydrogen bonding in PVA crystals. With the crystals of PVA destroyed, PVA molecules could form more interaction with each other. The disappear of the intensity of diffraction peak indicated that the addition of $\mathrm{MnCl}_{2} \cdot 4 \mathrm{H}_{2} \mathrm{O} /$ glycerin could effectively decrease the degree of crystallinity of PVA films.

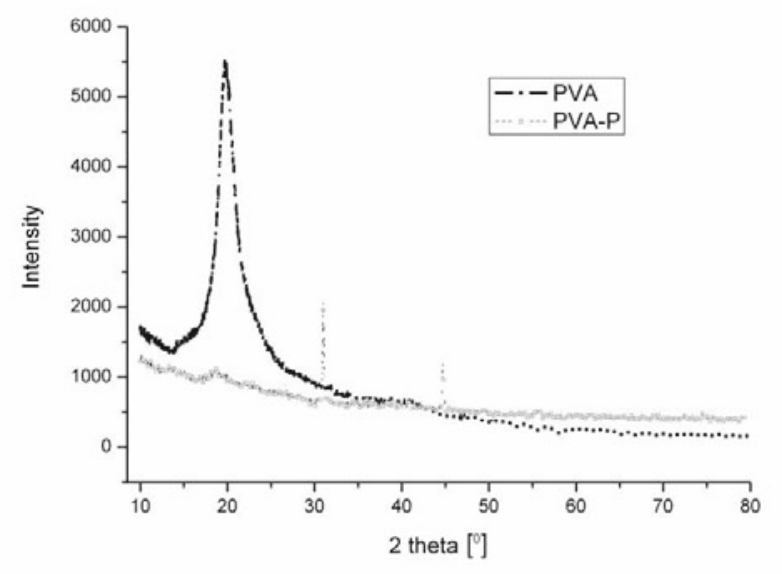

Figure 6. XRD curves of pure PVA and PVA -P

\section{CONCLUSIONS}

The complex plasticizer $\mathrm{MnCl}_{2} \cdot 4 \mathrm{H}_{2} \mathrm{O} /$ glycerin was proved to be with a high plasticizing effect for PVA by all the results in our article. $\mathrm{MnCl}_{2} \cdot 4 \mathrm{H}_{2} \mathrm{O} /$ glycerin could interact with PVA molecules and replace the hydrogen bonding within PVA molecules. The crystallization of PVA was interrupted and the intensity of the hydrogen bonding in PVA was reduced in the way. The complex plasticizer $\mathrm{MnCl}_{2} \cdot 4 \mathrm{H}_{2} \mathrm{O} /$ glycerin was proved to be with a high plasticizing effect for PVA by all the results in our article. $\mathrm{MnCl}_{2} \cdot 4 \mathrm{H}_{2} \mathrm{O} /$ glycerin could interact with PVA molecules and replace the hydrogen bonding within PVA molecules. The crystallization of PVA was interrupted and the intensity of the hydrogen bonding in PVA was reduced in the way. The $\mathrm{MnCl}_{2} \cdot 4 \mathrm{H}_{2} \mathrm{O} /$ glycerin complex plasticizer could improve the compatibility of
PVA, and the plasticized PVA films appeared a more continuous than pure PVA films. The thermal stability and the glass transition temperature of decreased with the addition of $\mathrm{MnCl}_{2} \cdot 4 \mathrm{H}_{2} \mathrm{O} /$ glycerin. The mechanical properties of PVA were improved significantly and the plasticized PVA films appeared a more tougher than pure PVA films after adding the complex plasticizer $\mathrm{MnCl}_{2} \cdot 4 \mathrm{H}_{2} \mathrm{O} /$ glycerin. It can also be expected that the complex plasticizer $\mathrm{MnCl}_{2} \cdot 4 \mathrm{H}_{2} \mathrm{O}$ /glycerin could play an important role in the polymer such as cellulose that contain many hydroxyl groups.

\section{ACKNOWLEDGEMENTS}

The authors thank Jiangsu Province Natural Science Foundation of China (Grant No. BK20141074), National Natural Science Foundation of China (Grant No. 31300490) and 948 of the State Forestry Project (2013-4-12) for the financial support during this study.

\section{LITERATURE CITED}

1. Vanheusden, K., Warren, W.L., Seager, C.H., Tallant, D.R., Voigt, J.A. \& Gnade, B.E. (1996). Mechanisms behind green photoluminescence in $\mathrm{ZnO}$ phosphor powders. J. Appl. Phys. 79, 7983. DOI: http://dx.doi.org/10.1063/1.362349

2. Takai, O., Futsuhara, M., Shimizu, G., Lungu, C.P. \& Nozue, J. (1998). Nanostructure of $\mathrm{ZnO}$ thin films prepared by reactive rf magnetron sputtering. Thin Sol. Films. 318 (1-2), 117-119. DOI: 10.1016/S0040-6090(97)01148-6.

3. Xiong, M., Gu, G., You, B. \& Wu, L. (2003). Preparation and characterization of poly (styrene butylacrylate) latex/ nano ZnO nanocomposites. J. Appl. Polym. 90, 1923-1930. DOI: 10.1002/app.12869.

4. El-Sawy, N.M., El-Arnaouty, M.B. \& Abdel Ghaffar, A.M. (2010). $\gamma$-Irradiation effect on the non-cross-linked and cross-linked polyvinyl alcohol films. Plast. Technol. Technol. Engine., 49(2), 169-177. DOI: 10.1080/03602550903284248.

5. Xueping, Z., Shenglin, L. \& Donglin, L. (2009). The effect of additives on the hydrogen storage properties of NaAlH. Inter. J. Hydro. Energy. 34(6), 2701-2704. DOI: 10.1016/j. ijhydene.2009.01.066.

6. Tharanathan, R.N. (2003). Biodegradable films and composite coatings: past, present and future. Trends in Food Science \& Technology. 14(3): 71-78. DOI: 10.1016/S0924-2244(02)00280-7.

7. Yan, R.X. (1998). Water-soluble Polymers (42). Beijing, China: Chemical industry press.

8. Chen, N., Li, L. \& Wang, Q. (2007). New technology for thermal processing of poly (vinyl alcohol). Plastics, Rubber and Composites. 36(7-8), 283-290. DOI: http://dx.doi. org/10.1179/174328907X237575.

9. Nishino, T., Kani, S., Gotoh, K. \& Nakamae, K. (2002). Melt processing of poly (vinyl alcohol) through blending with sugar pendant polymer. Polymer 43(9), 2869-2873. DOI: 10.1016/ S0032-3861(02)00059-9.

10. Liu, Z.Q., Feng, Y. \& Yi, X.S. (1999). Effects of glycerin and glycerol monostearate on performance of thermoplastic starch. J. Appl. Polym. Sci. 74: 2667-1674. DOI: 10.1023/A:1017589028611.

11. Alexy, P., Lacik, I., Simkova, B., Bakos, D., Pronayova, N., Liptaj, T., Hanzelova, S. \& Varosova, M. (2004). Effect of melt processing on thermo-mechanical degradation of poly(vinyl alcohol)s. Polym. Degrad. Stab. 85, 823-830. DOI: 10.1016/j. polymdegradstab.2004.02.011.

12. Wang, Q., Du, Yumin \& Fan Lihong. (2005). Properties of chitosan/poly(vinyl alcohol) films for drug-controlled release. J. Appl. Polym. 98, 774-779. DOI: 10.1002/app.21518. 
13. Wang, R., Wang, Q. \& Li, L. (2003). Evaporation behaviour of water and its plasticizing effect in modified poly (vinyl alcohol) systems. Polym. Int. 52, 1820-1826. DOI: 10.1002/ pi.1385.

14. Zidan, H.M. (2003). Structural properties of $\mathrm{CrF}_{3}$ and $\mathrm{MnCl}_{2}$ filled poly (vinylalcohol) films. J. Appl. Polym. 88, 516-521. DOI: $10.1002 /$ app.12044.

15. Ismail, H. \& Zaaba, N.F. (2011). Effect of additives on properties of polyvinyl alcohol (PVA)/tapioca starch biodegradable films. Polymer-Plastics Technology and Engineering, 50, 1214-1219. DOI: 10.1080/03602559.2011.566241.

16. Tang, X. \& Alavi, S. (2011). Recent advances in starch, polyvinyl alcohol based polymer blends, nanocomposites and their biodegradability. Carbohydr. Polym., 85(1), 7-16. DOI: 10.1016/j.carbpol.2011.01.030.

17. Zu, Y., Zhang, Y., Zhao, X., Shan, C., Zu, S., Wang, K. (2012). Preparation and characterization of chitosan-polyvinyl alcohol blend hydrogels for the controlled release of nano-insulin International. J. Biolog. Macromol. 50(1), 82-87. DOI: 10.1016/j.ijbiomac.2011.10.006.

18. Jiang, X.C., Jiang, T., Zhang, X.F., Zhang, X. \& Dai, H. (2012). Melt processing of poly (vinyl alcohol) through adding magnesium chloride hexahydrate and ethylene glycol as a complex plasticizer . Polym. Eng. 52, 2245-2252. DOI: 10.1002/ pen.23166.

19. Hualiu, Y. \& Xingdai, L. (2012). Improvement of Morphology, Structure, and Thermal Properties of Electrospun PVA/RSF Fiber Mats by $\mathrm{SiO}_{2}$. Appl. Mech. Mater. 1017(184-185), 1017-1020. DOI: 10.4028/www.scientific.net/ AMM.184-185.1017.

20. Jiang, X., Jiang, T., Zhang, X. \& Zhang, X. (2013). The plasticizing effect of calcium nitrate on poly (vinyl alcohol). Polym. Engine. \& Sci. 52(7), 1565-1570. DOI: 10.1002/pen.23377.

21. Jiang, X.C., Jiang, T., Zhang, X.F., Zhang, X. \& Dai, H. (2012). The plasticizing mechanism and effect of calcium chloride on starch/poly (vinyl alcohol) films, Carbohyd. Polym. 90, 1677-1684. DOI: 10.1016/j.carbpol.2012.07.050. 